\title{
Mental Mapping and Heritage Visitors' Spatial Perceptions
}

Visitors' activities tend to be spatially oriented in destinations. Mental mapping is a useful method for revealing how visitors spatially perceive tourism destinations. However, studies of this kind are under-researched in the tourism field. Therefore, this study investigates the ways in which visitors spatially perceive the World Heritage Sites (WHSs) of Macau through the use of mental maps drawn by a sample of 400 respondents. Comparisons of the mental maps revealed that respondents possessed a relatively limited spatial knowledge of the WHSs, and this recognition varied according to the gender, place of origin, travel mode, type of trip, social interaction with

local people, and length of stay. While the real life world of visitors was identified by mental mapping approach, some suggestions for formulating strategies is provided.

Keywords: mental map; perception; spatial distortion; direction, location; World Heritage Sites of Macau

\section{Introduction}

A questionnaire-based quantitative approach tends to provide a limited understanding of visitors' real life experiences in tourism destinations because of pre-set nature of questions designed by the researchers, which often restricts respondents' freedom of expression (Becken, 2007; Batra, 2008; Wichasin, 2011; Yankholmes \& Akyeampong, 2010). According to Young (1999), through mental mapping approach respondents can reveal their experiences, preferences, desires and knowledge without any restrictions, and without being led by the intentions of the researchers. Thereby, the limitations of questionnaire-based surveys might be overcome by the mental mapping approach. 
Mental maps, as Jansen (2011) mentioned, can reveal the interaction between an individual and the surrounding environment, and are used for comparing, analysing, displaying and eliciting mental models, providing many interpretations of people's spatial perceptions (Eden, 2004), giving respondents a chance to express themselves freely. The mental mapping approach can thus make up for the shortcomings of questionnaire surveys that impose a restriction on respondents' expressions. In addition to understanding respondents' spatial perceptions, mental maps are helpful in understanding in which recreational opportunities tourists partake (Walmsley \& Jenkins, 1992), and thus can contribute to formulating tourism planning development and promotion (Fridgen, 1987). Tourists' behaviours and experiences might be spatially oriented because their activities are mainly based in tourism destinations. Therefore, visitors' spatial perceptions of tourism destinations are very important for understanding visitor behaviour, enabling more effective management of tourism destinations.

Mental maps are defined as psychological representation of places revealed by simple paper and pencil or egocentric images of place of individuals based upon their interpretations of spatial attractiveness and their organization of spatial routines (Johnston et al., 2000). Mental maps, therefore, have long been used as a tool for presenting perceptions of an individual or a group of individuals such as perception of the location of a residential area (Lee 1985; Kim 1978; Kim, N. H., 1987), pupils' spatial perceptions (Kim, M. G., 1987; Choi 2008), and perceptions of foreigners about specific destination (Lee \& Shipton, 2009). According to Relph (1989), mental maps can be analyzed theoretically in terms of behavioral perspectives. Thus mental maps have been one of the principal concepts of behavioural geography (Johnston et al. 2000), providing insights into how visitors perceive destinations (Govers \& Go 2005; Rivero, 2009; Lopes, 2011; Matei et al., 2001; Kai et al., 2008; Jansen, 2011; Ortigueira \& Gómez-Selemeneva, 2011). However, the mental 
mapping approach, even though it has many benefits in studying how tourists understand their environment and can analyze tourism phenomena such as attitudes, perceptions and behaviours, has rarely been utilized in the study of tourism. The need to fill the gap becomes marked when we observe a congestion phenomenon that diminishes the quality of tourists' experience and causes environmental degradation (Lee \& Rii, 2016). Therefore, in this study the authors focus on a spatial perception of World Heritage Sites (WHSs), aiming to present both a theoretical underpinning of mental maps as well as a grasp of their empirical modalities. Since most perception-related tourism studies that use a quantitative approach provide a limited understanding of visitors' spatial perceptions and real life world in tourism destinations, this study therefore considers the significance of the following issues: respondents' spatial perceptions revealed by mental maps and the factors which impact upon the spatial perceptions of the WHSs.

\section{Mental Map}

\section{What is a mental map?}

A mental map is defined as spatially organized preferences because it reflects individuals' spatial proclivities as for example the tendency for people to draw detailed mental maps of familiar places, omitting unfamiliar places (Johnston et al., 2000). It is a useful tool for representing people's real life worlds because they can help to reveal people's memories, experiences and associations (Choi, 2008). A mental map can also be described as a cognitive map, awareness space, action space or imaginary map as it can reveal the individual's imagining of an environment (Choi, 2008). Unlike real maps, people's mental maps differ because people tend to draw what they know or where they 
know (Kim et al., 1999), and thus mental maps are useful for understanding visitors' spatial behaviour and real life experiences in tourism destinations.

\section{Which factors influence the mental maps?}

According to previous studies, the accuracy and completeness of mental maps are influenced by various factors such as people's experiences (Walmsley \& Jenkins, 1992; Brown \& Broadway, 1981), place of origin (Young, 1999), type of trip (Young, 1999), length of stay in an area, socioeconomic status, education, gender, age, and mode of travel (Moore, 1979; Brown \& Broadway, 1981; Kim, N. H., 1987; Orleans, 1973). For example, in terms of gender, the mental maps of males tend to reveal more composite views of destinations, while those of females have a tendency to show more detailed imagery of their immediate surroundings (Goodchild, 1974). In the case of the latter, this may be because females have historically been spatially constrained due to their roles as mothers and housewives and the restrictions imposed upon them by parents and teachers (Brown \& Broadway, 1981). The mode of travel also affects the style of people's mental maps. For example, the mental maps of drivers tend to be closer to real maps than those of people who use passive modes, such as mass transit (Brown \& Broadway, 1981; Young; 1999). This study tries to explore the affecting factors of respondents' spatial perceptions in the case of Macau's WHSs using the mental mapping technique.

\section{How are mental mapping data analysed?}

According to Lynch (1960), human beings see the environment as built surroundings comprising paths (passageways along which people move), edges (barriers that divide one area into different areas), districts (regions with an identifiable character), nodes (strategic points for travel) and 
landmarks (mechanical reference points). Previous studies have tested the five elements of Lynch to analyse the image of destinations (Lee, 1980; Young; 1999; Lee \& Shipton, 2009). Together, these elements can reveal a city's image (Lynch, 1960) and can provide the unit of analysis of the mental maps drawn (Knox \& Marston 2004). This study therefore adopted Lynch's approach in the context of Macau's WHSs. Mental maps usually comprise two distinctive styles: the first is a free-hand style called the Lynchian-style (Lynch, 1960), whilst the second involves ranking items and it called the Gouldian-style (Gould, 2000). This study used Lynchian-style, free-hand drawn maps because this technique helps to minimize the influence of the researchers' subjectivity (Pocock, 1978).

\section{What are the limitations of the mental mapping approach?}

The literature on the mental mapping approach generally agrees that mental mapping is a useful means for understanding individual perceptions (Moore et al., 1998; Matei et al., 2001). However, despite its usefulness, the mental mapping approach is not without its critics. It has been argued, for example, that the constructs of a mental map cannot be assumed to relate explicitly to an individual's behaviour and that the landscape is often overlooked as the focal point of drawn images (Jackson \& Smith, 1984). Furthermore, the information in a mental map represents a simplified version of reality that is distorted because it has been filtered several times; it also reflects the limitations of the available information (Knox \& Marston, 2004). In addition, it is impossible to have a complete cognitive image of a destination because the image may be perceived differently depending on the individual's mental state (Jenkins \& Walmsey, 1993). In other words, people tend to filter out important information and places, consciously or unconsciously, if the information does not fit with what they know. Accordingly, respondents who 
are more familiar with the surrounding environment generate more detailed mental maps (Golledge \& Stimson, 2007), indicating that visitors who are more familiar with the WHSs might be able to create mental maps of them that are similar to real maps.

\section{Applications of mental maps in tourism research}

Since a picture is worth a thousand words (Pizam \& Mansfeld, 1999), mental mapping, as one of the principal concepts of behavioural geography (Johnston et al. 2000), is a useful technique for analyzing, representing and identifying perceptions with many interpretations (Eden, 2004;

Xiang \& Formica, 2007). However, the scope tends to be limited to the general field of tourism. Mental mapping, which can be defined as cognitive mapping (Choi, 2008), has been used to examine visitors' understandings of destinations in the tourism field (Walmsley \& Jenkins, 1991, 1992; Jenkins \& Walmsley, 1993; Young, 1999; Lankford et al., 2005); to elicit perceptions of industry executives (Costa \& Teare, 2000; Xiang \& Formica, 2007); to formulate tourism strategies (Hay \& Yeoman, 2005; Copland, Garnham \& Canava, 2004); and to examine complexity in tourism policies (Farsari, Butler, \& Szivas, 2011). Therefore, this study applies the mental mapping technique to provide a better understanding of real life world of visitors to Macau's World Cultural Heritage Sites and to reframe its contribution to tourism research.

\section{Study methods}

As discussed above, the use of a questionnaire may carry implicit bias as it may restrict respondents' freedom of expression in accordance with the outlook of the researchers. In order to address this problem when studying the Macau WHS, the authors combined two approaches: a questionnaire survey approach and a mental mapping analysis. What should also be noted is that the authors are 
aware of reservations concerning the use of multi-methods to increase he validity of findings and have factored them into this study (Clark, Riley, Wilkie and Wood, 1998)

The survey questionnaire consisted of two parts. The first part of survey questionnaire was developed to measure the variables affecting visitors' spatial perceptions, consisting of two subsections: the first sub-section was devoted to socio-demographic data such as gender, age, place of origin, academic year; the second concerned with social interaction with local residents, travel mode, type of trip, visiting times, and length of residence based on previous studies (Walmsley \& Jenkins, 1992; Brown \& Broadway, 1981; Moore, 1979; Kim, N. H., 1987; Orleans, 1973; Young, 1999).

The second part of the questionnaire asked respondents to draw a mental map of the WHSs of Macau as a free-hand map in the Lynchian style (Lynch 1960; Young 1999). These mental maps were drawn to illustrate the respondents' spatial knowledge, experience and preferences concerning the various parts of the WHS of Macau. Most respondents spent 45 minutes drawing their mental maps and filling out the questionnaire. Respondents were not influenced by any existing maps such as a paper maps or electronic maps or by other individuals while drawing their images under the supervision of four trained research assistants. When drawing mental maps, a sheet of A4-paper with a brief introduction and explanation on how to draw a sketch map of the WHSs of Macau at the top and blank space on the rest of the page was provided.

The results of pre-test as a part of preparatory work of this research were used to modify the questionnaire and to ensure its validity and reliability. The pilot survey was conducted in the Macau University of Science and Technology in March, 2013. Forty questionnaires were sent out 
and 36 valid responses were received. After the pre-test, the above two parts of questionnaire were modified and finalized, reflecting the problems suggested by respondents. A revised version of questionnaire was drawn up in English and in traditional Chinese characters (the official text of Macau) using back translation to ensure that the versions were consistent in terms of meaning.

Regarding the sampling, most mental maps in related studies tend to collect data from students (Kim, 1978; Lee, 1985; Kim N. H., 1987; Kim, M. G., 1987; Choi, 2008) because the active cooperation of respondents is required in order to get access to visitor's representations via the use of mental mapping (Dellaert et al., 2013). Thus, the target group for this research consisted of university level students who had taken an excursion to the WHSs of Macau because it was very difficult for other target groups of visitors to draw mental maps on the crowded streets of the Macau's WHSs. In selecting the respondents, the quota sampling was based on the percentage of different universities' students. The authors divided the target sample of this paper into five groups: from the University of Macau (UMAC), Macau Polytechnic Institute (IPM), Institute for Tourism Studies (IFT), Macau University of Science and Technology (MUST), and Others. The percentage of the total contributed by each group was calculated. Then the sample number for each group based on their proportion was determined: UMAC $(n=109), \operatorname{IPM}(n=22)$, IFT $(n=$ 9), MUST ( $n=249)$ and 25 from others. The data were collected in the four universities in Macau from summer of 2013 to spring of 2016. As Bartlett et al. (2001) and Gayle (2011) suggested, a sample size would need at least 384 completed questionnaires, for ensuring an adequate sample to conduct analyses. A total of 400 valid questionnaires were obtained at various locations on the campuses of the universities such as classrooms, libraries, dormitories and canteens.

\footnotetext{
***Please place Table 1 here***
} 
Table 1. The proportion of students in the universities of Macau

All collected data from the questionnaire survey and mental mapping were transferred to a SPSS 22.0 document for detailed analyses. Since the five basic coding categories of Lynch (1960) are traditionally used as initial organizational units for coding map content (Young, 1999), the mental mapping data were classified and coded based on the five categories of Lynch (1960) such as paths (streets along which most visitors move), nodes (strategic points for travelling such as the intersection of streets), edges (barriers between WHS and commercial area), districts (regions with an identifiable character, i.e. Central Business District and WHS), and landmarks (mechanical reference points such as the historical buildings of the WHSs of Macau). Coding was created using the mental map data following the five categories, but spatial distortions of drawn elements such as location and direction were also checked and counted. Because the use of such rich information from mental maps raises reliability issues when coded (Young, 1999), the data were quantified by double checking for establishing inner-coder reliability (Dooley, 1984, p. 62; Tinsley \& Weiss, 1975, p. 359). The outcomes of the mental maps and questionnaires were linked in a quantitative way to test the variables influencing spatial perceptions of the WHSs in Macau.

The statistical approaches used comprised descriptive analysis, inter-coder reliability analysis, chi-square test, and multivariate analysis of variance (MANOVA). The Cronbach's alpha coefficient for the goodness of fit, number of paths, number of edges, number of landmarks, number of districts, and number of nodes was 0.760 , and for the number of distortions of direction and location was 0.990, indicating that the data possessed an acceptable level of reliability (Nou, 2001). 


\section{Case study area: The WHSs of Macau}

Historically Macau was a lucrative and strategic port based on three small offshore islands that were under Portuguese administration from the mid-16th century until 1999, when it was returned to Chinese sovereignty as a Special Administrative Region (SAR). The 'Historic Centre of Macau' was inscribed, using UNESCO's nomenclature, as a World Heritage Site in 2005 and it comprises a number of significant buildings, notably churches, government buildings and forts. The WHSs of Macau are a collection of 25 locations representing the mixed cultures of Chinese, Portuguese and others (e.g. British). Among the 25 locations, the Ruins of St. Paul's and the A-Ma temple functioned as a symbol of Macau are the most popular places resulting in permanent physical congestion caused by short-stay tourists, while the other locations are under-used by visitors (Lee \& Rii, 2016). Since Macau has overtaken the well-known casino city of Las Vegas in terms of revenue, it remains the premier gaming centre of the world, but the Macau government is keen to diversify its brand and to place emphasis on Macau's other attractions, such as its cultural heritage.

\section{Results}

\section{Characteristic of the respondents}

The data were obtained from a sample of 400 people who completed the mental mapping exercise with a slight bias in favor of females. The majority (62.0\%) originated in Mainland China and had come to study in Macau and only 37 percent reported residing in Macau on a permanent basis. About 40 percent of a sample identified themselves as post-graduate students while the rest were undergraduates. Regarding their mode of travel, 74.5 percent of respondents stated that they were passengers on public transport. The overwhelming majority of the sample (81.8\%) reported having 
interacted with local people, and over half of the sample (58.5\%) stated they had visited the WHSs of Macau more than five times. The length of stay in Macau varied considerably with the two major sections of the sample reported either being in Macau for only one year or less (34.8\%) or living there for over five years $(48.1 \%)$.

*****Please place Table 2 here*****

Table 2. The demographic profile of the respondents

\section{The effects of independent factors on mental map content}

Since a multivariate analysis of variance (MANOVA) is useful for analyzing variations in map complexity and detail among the main independent variables (Young, 1999), a MANOVA was chosen to assess the effects of independent factors on mental maps elements such as paths, nodes, districts, edges and landmarks. As shown in Table 3, the mental maps elements drawn by the respondents were statistically correlated with social interaction with local residents and length of residence. For example, those who had partaken in social experiences with local people tended to be more spatially orientated in terms of the recognition of nodes, districts and landmarks. The respondents who had contact with local people while travelling the WHSs had a superior spatial memory to recall such mental map elements, meaning contact with local people might help enlarge the spatial awareness of respondents in the WHSs. The length of residence in Macau had an effect on the number of paths. Respondents who stayed in Macau for one year tended to recognize the paths of Macau's WHSs more clearly than those of visitors with a longer length of residence. This tendency is at odds with previous studies, which found that visitors with longer stays have more spatial knowledge of destinations (Moore, 1979; Brown \& Broadway, 1981; Kim, M. G., 1987; 
Orleans, 1973). It may be that visitors who have lived in Macau for one year have adopted an exploratory mode that is somewhat akin to tourists, whereas those who lived there longer may have become indifferent and less like tourists and were therefore less able to recall paths.

The MANOVA design also explored the two-way interactions between every single pairwise combination of independent variables (Young, 1999). For example, female respondents who had contact with local people while travelling the WHSs tended to have more spatial knowledge in recognizing the paths, nodes and landmarks more than male respondents $(F=1.859, p<.05)$. The mean score on the number of paths $(F=3.321, p<.05)$, nodes $(F=3.496, p<.05)$ and landmarks $(F=7.635, p<.05)$ drawn were significantly higher for female respondents than for male ones. This result is not line with McGurnness and Sparks (1979) who found that females tend to recall fewer paths than males. As this sample comprised students, it may reflect the fact that females have a tendency to obtain better results at school than males. With the exception of the age group 29-39, only a small proportion $(2.1 \%)$ of most age groups who had social interaction with local people tended to recall more edges than those of age groups who had no social experience with residents (Figure 4). This means that the social contact between visitors and residents may contribute to enlarging visitors' spatial knowledge and tourist space.

$$
\text { *****Please place Table } 3 \text { here } * * * * *
$$

Table 3. The effects of independent variables on mental maps elements

\section{The effects of independent factors on spatial distortion}

In order to understand the relationship between the spatial distortion of direction and the independent variables, chi-square analysis tests were employed. As shown in Table 4, there was a 
statistically significant relationship between the spatial distortion of direction and the independent variables such as gender, place of origin, and travel mode (driver and passenger), social interaction with local people, type of trip and length of residence. It is noteworthy that female respondents $(n=134,63.2 \%)$ had a tendency to distort the directions when they drew the WHSs of Macau more than male respondents $(n=78,36.8 \%)$ as shown in Map 1. This might be in line with Pocock (1978) who emphasized that males tend to recognize the pattern of roads more than females. In addition, the respondents who came from Mainland China $(n=160,75.5 \%)$ tended to distort the direction more than the respondents born in Macau $(n=50,23.6 \%)$, indicating local respondents are either more spatially oriented than mainlanders or are simply more familiar with their environment are either. This result is likely to be in line with those of previous studies, which found that local visitors have more spatial knowledge than non-local visitors (Young, 1999; Walmsley \& Jenkins, 1992; Prentice \& Andersen, 2000; Hunter \& Suh, 2007).

$$
\text { *****Please place Table } 4 \text { here } * * * * *
$$

Table 4. The effects of independent factors on the spatial distortion of direction *****Please place Map 1 here*****

\section{Map 1. Spatial distortion: Gender difference}

Note: Male visitors tend to recognize the direction of WHSs exactly. Female visitors distort the direction, revealing the direction of North as the South.

The chi-square analyses were also used to investigate the association between the spatial distortion of location and the independent variables. According to the results, there was a statistically significant relationship between the spatial distortion of location and the independent 
variables such as gender, place of origin, travel mode, social interaction with local people, type of trip, and length of residence. For example, female respondents $(n=134,62.6 \%)$ had a tendency to distort the locations of the WHSs of Macau when they drew it more than male respondents $(\mathrm{n}=80$, $37.4 \%)$. With regard to mode of travel, passengers $(n=168,84.0 \%)$ using bus or foot had a tendency to distort more locations than drivers $(n=32,15.0 \%)$. This result is likely to be in line with Young (1999) who insisted that drivers were engaged in a way-finding tasks and were consequently more spatially oriented than passengers. The length of residence in Macau might be also an influencing factor on spatial perceptions based on this result. The respondents who stayed in Macau for one year $(n=88,41.4 \%)$ were more apt to distort the locations of the WHSs of Macau than those who had stayed for two years $(n=8,3.7 \%)$ or three years $(n=21,9.8 \%)$ relatively.

$* * * * *$ Please place Table 5 here*****

Table 5. The effects of independent factors on the spatial distortion of location

\section{Tourist space revealed by mental maps}

The hand-drawn mental maps provide an insight into the tourist vision of the WHSs of Macau. Significantly, the landmarks selected by the respondents tended to focus on Macau's heritage attractions, the most frequently mentioned being the Ruins of St. Paul's (33.4\%), the A-Ma Temple (14.2\%), and the Mount Fortress (10.8\%). This finding would appear to indicate that respondents' tourism activities were mainly concentrated on only 3 locations among the 25 locations shown in Table 6. What is especially noteworthy is that by the $21^{\text {st }}$ century the Ruins of St. Paul's had become, among all 25 locations listed, a kind of symbolic altar of Macau, its premier cultural heritage attraction (Dewar, du Cros \& Li, 2012). As a result, the Ruins of St. Paul's have been 
chosen by many respondents as their major attraction. Not only this attraction relates closely to the religious and cultural history of Macau, but it is also very well signposted and readily accessible. However, it is difficult on the basis of this study to ascertain how deeply these respondents engaged with the attraction as there is little local interpretation concerning what is a symbolically complex monument, and it is suggested that much of their involvement could simply be a limited form of romanticism. The least popular landmarks enjoying less than 0.5 percent of respondents' attention included St. Lawrence's church (0.4\%), St. Anthony's Church (0.3\%), Casa Garden (0.2\%) and Protestant Cemetery (0.2\%). This result is in line with du Cros (2007) and Io (2011) who revealed that the most popular locations of Macau's WHSs are the Ruins of St. Paul's and the A-Ma temple. We can therefore summarize that it is these three destinations that leave the greatest impression on visitors, possibly because they are the best signposted and have the highest 'must see' quality. As has been indicated by other studies (du Cros, 2009; Io, 2011; Lee \& Rii, 2016), visitors often stay no longer than two hours at the WHSs of Macau mostly visiting the Ruins of St. Paul's, the Mount Fortress and the A-Ma temple, but this may not be due to a lack of interest but to a lack of facilities such as benches to enable them to rest. The climate of Macau may also be a factor since visitors may not wish to linger long in the humid climate or be exposed to strong sunlight.

*****Please place Table 6 here $* * * * *$

Table 6. Frequency analysis of drawn landmarks in mental maps

\section{Conclusion}

Tourists' activities and behaviours tend to be spatially oriented in tourism destinations. However, the tourism studies on visitors' spatial perceptions are limited. Thus this study proposed mental 
maps as the product both of immediate sensation and of memory of past experience, which are used to interpret information and to guide action (Lynch, 1960) and provide insight in spatial learning and the structure and composition of tourism destination experiences (Young, 1999).

Since most tourism studies are likely to provide a limited understanding of visitors' spatial perceptions, two research issues were identified to present both theoretical support for mental maps and an understanding of their empirical relevance in heritage sites such as Macau. The first research issue was: "How do the mental maps reveal respondents' spatial perceptions?" According the results, most of the historical sites in the WHSs of Macau are under-used and only three attractions are over-used by visitors. There is the risk that these sites will remain overcrowded, unless ways of directing visitors to other sites with promotion of the under-used attractions are explored by the authorities of Macau. However, as three of the sites are so iconic, it is hard to see how some overcrowding can be avoided. As this results indicated, the mental mapping technique is useful to reveal respondents' real tourist space in tourism destinations, avoiding researcher influence on map creation (Young, 1999). The mental mapping data of this study revealed respondents' real life worlds relating to the Macau WHSs, focusing on the three locations. Therefore the mental mapping approach may provide insight for understanding which tourism opportunities visitors partake in (Walmsley \& Jenkins, 1992).

The second issue was: what are the variables affecting towards the spatial perceptions of the WHSs of Macau? This study proved that respondents' spatial knowledge related to the paths, nodes, edges, districts, and landmarks varied according to social interaction with local residents and length of residence. The variable of social interaction with local residents might contribute to enlarge the respondents' spatial knowledge towards the WHSs of Macau. The respondents who 
engaged in social interaction with local people had a tendency to recognize more nodes, districts and landmarks of the WHSs of Macau than those who had no interaction with local residents, indicating that the social engagement between visitors and residents might be useful for recognizing WHSs spatially.

In terms of the mental map style, the spatial distortion of respondents tend to be associated with the independent variables such as gender, place of origin, and travel mode (driver and passenger), social interaction with local people, type of trip and length of residence. Regarding gender, it is notable that female respondents had a tendency to distort the directions and locations when they drew the WHSs of Macau more than male respondents, possibly meaning that male visitors are more spatially oriented than female visitors (Goodchild, 1974; Brown \& Broadway, 1981). However, this point of view may need to consider Young's suggestions (1999) that females would use a more intuitive style of mapping while males prefer functional style. Among the relevant variables, especially, the variable of travel mode tended to have a stronger statistical relationship with the spatial distortion of location and direction. Even though visitors have to walk to participate in sightseeing around the WHSs of Macau because it is very difficult for drivers to travel to the WHSs due to the limited parking space (Io, 2011), passengers tend to distort more directions and locations than drivers. This result is supported by Young (1999), who indicated that drivers tend to be engaged in a way-finding tasks and have more environmental knowledge than passengers, providing an indication of the effectiveness of passenger management strategies rather than driver management in the small-scale WHSs.

In conclusion, mental maps give a chance to respondents in order that they express their real life world in tourism destinations, providing useful information towards visitors' experiences and 
behaviours. However, its application to tourism research is limited. Accordingly, this study was designed to enlarge the concepts of mental maps to tourism destinations, applying its concepts to the WHSs of Macau. Based on the results of this study, respondents' tend to express their familiar places through mental maps. Therefore the mental mapping approach might be useful to formulate tourism strategies (Hay \& Yeoman, 2005; Copland, Garnham \& Canava, 2004) and contribute to more effective tourism planning development and promotion (Fridgen, 1987), since it gives a fairly reliable insight into the spatial knowledge of visitors. This present study dealt with the affecting variables with the sample, providing opportunity in order to know visitors' real life world in tourism destination. The image of WHSs by the mental mapping is not solely the result of external characteristics but is a product of the respondents. Thus as Lynch (1960) said, it would be possible to improve the image quality by education. Therefore, future studies could be conducted on the ways by which one can teach visitors to be well spatially oriented to their visiting WHSs, considering the reasons of the lack of understanding of the WHSs image as a total field. In addition, regarding the sampling for mental map data, there still exist limitations in the target sample consisted of university level students who took an excursion in the WHSs of Macau because the active participation of respondents and articulate volunteers are needed to draw the mental maps (Lynch, 1960; Dellaert et al., 2013). Thus, future research is required to be extended the range of visitors who visit a sensitive tourism destination influenced by tourists' behaviours, considering the inducement of visitors' active cooperation.

\section{References}

Bartlett, I. J., Kotrlik, J. W. \& Higgins, C. C. (2001). Organizational research: Determining appropriate sample size in survey research. Inform Technol Learn Perform, 19, 43-50. 
Batra, A. (2008). Foreign tourists' perception towards personal safety and potential crime while visiting Bangkok. International Journal of Tourism and Hospitality Research, 19(1), 89-101.

Becken, S. (2007). Tourists' Perception of International Air Travel's Impact on the Global Climate and Potential Climate Change Policies. Journal of Sustainable Tourism, 15(4), 351-368.

Boo, S., \& Gu, H. (2010). Risk perception of mega-events. Journal of Sport \& Tourism, 15(2), $139-161$

Brown, M. A. \& Broadway, M. J. (1981) The Cognitive Maps of Adolescents: Confusion about Inter-Town Distances. The Professional Geographer, 33(3), 315-325.

Choi, S. A. (2008). Understanding of Children's Life World Revealed in Mental Maps (Unpublished Master of Arts dissertation). Cheongju, South Korea: Korea National University of Education.

Clark, M., Riley, M., Wilkie, E. and Wood, R.C. (1998) Researching and Writing Dissertations in Hospitality and Tourism. London: International Thomson Business Press

Copland, P., Garnham, B. and Canava, R. Y. (2004). Sustainable Tourism in Queenstown: An Application of Cognitive Strategic Mapping. In K. A. Smith and C. Schott (eds.), Proceedings of the New Zeeland Tourism and Hospitality Research Conference 2004. Wellington, 8-10 December, 43-54.

Dellaert, B., Arentze, T., Chorus, C. G., Oppewal, H., \& Wets, G. (2013). Workshop report: mental representations and discrete choice behaviour: state-of-the-art and avenues for future research. Choice Modelling: The State of the Art and the State of Practice, 107.

Dewar, K., du Cros, H., \& Li, W. (2012). The search for World Heritage brand awareness beyond the iconic heritage: a case study of the Historic Centre of Macao. Journal of Heritage Tourism, 7(4), 323-339.

Dooley, D. (1984). Social research methods. New Jersey: Prentice-Hall. 
du Cros, H. (2007). Too much of a good Thing? Visitor congestion management issues for popular World Heritage tourist attractions. Journal of Heritage Tourism, 2(3), 225-238. doi:10.2167/jht062.0

du Cros, H. (2009). Emerging Issues for Cultural Tourism in Macao. Journal of Current Chinese Affairs, 1, 73-99.

Eden, C. (2004). Analyzing cognitive maps to help structure issues or problems. European Journal of Operational, 159 (3), 673-686.

Fridgen, J. D. (1987). Use of cognitive maps to determine perceived tourism regions. Leisure Sciences: An Interdisciplinary Journal, 9(2), 101-117.

Gayle, J. (2011). Tourism Research (2 ${ }^{\text {nd }}$ ed.). Australia: Wiley.

Goodchild, B. (1974). Class differences in environmental perception: an exploratory study. Urban Studies, 11(2), 157-169.

Golledge, R. G. \& Stimson, R. J. (1997). Spatial Behavior: A Geographic Perspective. New York: Guilford Press.

Gould, P. R. (2000). On mental maps, Discussion paper no. 9, Ann Arbor: Michigan InterUniversity Community of Mathematical Geographers. In R. J. Johnston, D. Gregory, G. Pratt, \& M. Watts, The dictionary of human geography (4 ${ }^{\text {th }}$ ed.) (pp. 498-499). Oxford: Balckwell.

Govers, R. \& Go, F. M. (2005). Projected destination image online: Website content analysis of pictures and text. Information Technology \& Tourism, 7, 73-89.

Hay, B. \& Yeoman, I. (2005). Turning scenarios into a strategy map: Our ambition for Scottish tourism. Journal of Vacation Marketing, 11(1), 89-102.

Hunter, W. C. \& Suh, Y. K. (2007). Multimethod research on destination image perception: Jeju standing stones. Tourism Management, 28(1), 130-139.

Io, M. U. (2011). Can the Historic Center of Macao be a Popular Tourist Attraction? Examining the Market Appeal from Tour Marketers’ Perspective. Journal of Quality Assurance in Hospitality \& Tourism, 30 (2), pp. 58-72.

Jackson, P. \& Smith, S. J. (1984). Exploring social geography. London: Allen \& Unwin. 
Jansen, J. (2011). Tourist Familiarity in Amsterdam: Route choice behavior of (un)familiar domestic tourist within Amsterdam 's inner city (Unpublished Master's Thesis). Netherlands: Utrecht Publishing \& Archiving Services.

Jenkins, J. M. \& Walmsley, D. J. (1993). Mental Maps of Tourists: A Study of Coffs Harbour, New South Wales. GeoJournal, 29(3), 233-241.

Johnston, R. J., Gregory, D., Pratt, G. \& Watts, M. (2000). The dictionary of human geography ( $4^{\text {th }}$ ed.). Oxford: Blackwell.

Kai, B., Tian, Y. S. \& Peng, Z. (2008). Applying Cognitive Map to Analyze Factors Influencing Tourist Decision-Making: A Case Study in Xi' an City. Resources Science, 30(2), 313-319.

Kim, C. H., Ham, T. G., Kim, G. Y., \& Lee, M. S. (1999). Analysis of spatial recognizability from mental map. Journal of Photo Geography, 10(1), 21-41 (Seoul: South Korea).

Kim, C. Y. (1978). The Study of Spatial Perception of Students in Cheongju City. Geography of Sangdang, 2, 64-71 (Cheongju: South Korea).

Kim, M.G. (1987). An Analysis of the Pupils'Spatial Perception by Mental Maps: -An Empirical Study of the Pupils from Third to Sixth Grades in Taegu City. Journal of Geographical Study, 12, 17-33.

Kim, N. H. (1987). A Study of Mental Maps of High-School Students in Seoul. Journal of Geography Education, 18, 22-37.

Knox, P. L. \& Marston S. A. (2004). Human Geography. New Jersey: Pearson Education Inc.

Kuenzel, S., \& Katsaris, N. (2011). Discrepancies between tourists' and managers' perceptions of service Failures and service recoveries in Hotels. International Journal of Business Research, 11(5), 16-25.

Lee, H. Y. (1985). The Mental Maps and Information Surfaces of Korea-In Case of Pupils and Students in Pusan City. Journal of Sadae, 157-178 (Seoul: South Korea).

Lee, J. S. (1980). Urban structure of Honolulu city. National Planning, 15(1), 99-110. 
Lee, M. Y. \& Rii, H. (2016). An Application of the Vicious Circle Schema to the World Heritage Site of Macau. Journal of Heritage Tourism, 11(2), 126-142, doi $=10.1080 / 1743873 X .2015 .1045298$

Lee, Y. H. \& Shipton, N. J. (2009). The Image Foreign Teachers have of Seoul: How is Seoul being perceived?. Journal of Photo Geography, 19(4), 1-14 (Seoul: South Korea).

Lopes, S. D. F. (2011). Destination image: Origins, Developments and Implications. Revista de Turismoy Patrimonio Cultural, 9 (2), 305-315.

Lu, Z., \& Feng, Z. (2010). Perceptions of Chinese and International Tourists on China Hotel Service Quality. Journal of China Tourism Research, 6(1), 73-82.

Lynch, K. (1960). The Image of the City. Cambridge, MA: MIT Press.

Mahar, S. S., \& Bagri, S. C. (2010). Tourism in the Himalayas: An Evaluation of Tourist Perception, Expectation Quotient and Satisfaction Level in the Bhilangana River Valley of Uttarakhand State. Journal of Tourism, 11(1), 21-42.

Matei, S., Ball-R., S. J. \& Qui, J. L. (2001). Fear and Misperception of Los Angeles Urban Space: A Spatial-Statistical Study of Communication-Shaped Mental Maps. Communication Research, 28 (4), 429-463.

McGuinness, D., \& Sparks, J. (1979). Cognitive style and Cognitive Maps: Sex Differences in Representations. Journal of Mental Imagery, 7, 101-118.

Moore, K., Simmons, D. G. \& Fairweather, J. R. (1998). Visitor Decision Making, On-Site Spatial Behaviours, Cognitive Maps and Destination Perceptions: A Case Study of Kaikoura. Report for Tourism Research and Education Centre (TREC), Report No. 4.

Nou, H. J. (2001). Research method and statistical analysis by the Korean SPSS 10.0. Seoul, South Korea: Heungsul Publishing.

Orleans, P. (1973). Differential cognition of urban residents: effects of social scale on mapping. In R. M. Downs \& D. Stea (Eds.), Image and Environment: Cognitive Mapping and Spatial Behavior (pp.115-130), New Brunswick, NJ: Aldine Transaction Publishers. 
Ortigueira, L. C. \& Gómez-Selemeneva, D. G. (2011). Critical success factors of a tourist destination in the Caribbean, Proceedings of the International Conference on Tourism \& Management Studies, volume 1.

Pizam, A., \& Mansfeld, Y. (1999). Consumer behavior in travel and tourism. Psychology Press.

Pocock, D., (1978). Images of the urban environment. London, UK: The Mcmillian press.

Prentice, R., \& Andersen, V. (2000). Evoking Ireland: modeling tourism propensity. Annals of Tourism Research, 27(2), 490-516.

Qeed, M. A. A., Shihabi, O. A., Hasoneh, A., \& Aladwan, A. S. (2010). The European Tourist Perception Concerning the Jordanian Touristic Package. International Journal of Business and Management, 5(11), 84-96.

Relph, E. (1989). Geographical experiences and being in the world: the phenomenological origins of geography. In K. Soini (2001). Exploring human dimensions of multifunctional landscapes through mapping and map-making. Landscape and Urban Planning, 57, 225239.

Rivero, C. R. (2009). Impacts of music festivals on tourists' destination image and local community: Case Study: WOMAD and CONTEMPOPRANEA Festivals in Extremadura (Spain) (Unpublished Master's Thesis). UK: Bournemouth University.

Siri, R., Kennon, L., Josiam, B., \& Spears, D. (2012). Exploring Indian Tourists' motivation and Perception of Bangkok. Tourismos: an International Multidisciplinary Journal of Tourism, $7(1), 61-79$.

Tinsley, H. E. A., \& Weiss, D. J. (1975). Interrater relaliability and agreement of subjective judgements. Journal of Counseling Psychology, 22, 358-376.

Xiang, Z., \& Formica, S. (2007). Mapping environmental change in tourism: A study of the incentive travel industry, Tourism Management, 28(5), 1193-1202.

Walmsley, D. J. \& Jenkins, J. M. (1991). Mental maps, locus of control and activity: A study of business tourists in Coffs harbour. The Journal of Tourism Studies, 2(2), 36-42.

Walmsley, D. J. \& Jenkins, J. M. (1992). Tourism cognitive mapping of unfamiliar environments. Annals of Tourism Research, 19 (2), 268-286. 
Wichasin, P. (2011). A study of risk perception and prevention of international backpackers in Thailand. International Journal of Management Cases, 13(3), 515-523.

Yankholmes, A. K. B., \& Akyeampong, O. A. (2010). Tourists' Perceptions of Heritage Tourism Development in Danish-Osu, Ghana. International Journal of Tourism Research, 12(5), 603-616.

Young, M. (1999). Cognitive Maps of Nature-Based Tourists. Annals of Tourism Research, 26(4), 817-839.

Zhang, C. Z., Xu, H. G., Su, B. T., \& Ryan, C. (2009). Visitors' perceptions of the use of cable cars and lifts in Wulingyuan World Heritage Site, China. Journal of Sustainable Tourism, $17(5), 551-566$.

Zhou, Y. (2006). Government and Residents' Perceptions towards the impacts of a Mega Event: the Beijing 2008 Olympic Games (Unpublished Doctoral dissertation). Hong Kong: The Hong Kong Polytechnic University.

Zikmund, W. G. (2003). Business Research Methods (7th ed.). Ohio: ThomsonSouth-Western. 